\section{JCL}

Journal of the College of Languages

Open Free Access, Peer Reviewed Research Journal

Est.1994

\section{http://jcolang.uobaghdad.edu.iq}

P-ISSN: 2074-9279

E-ISSN: 2520-3517

2022, No.(45)

Pg. 248-286

\title{
The Role Of Historical Memory In Promoting The \\ Concept Of Belonging To The Homeland In A Novel \\ "Mazurka For Two Dead Men" Of The Spanish Novelist \\ Camilo Jose Cela
}

\section{Asst. Professor Qasem Mohammed Helal Saleem (Ph.D.)}

E-mail: dr.qasem@tu.edu.iq

University of Tikrit,College of Arts,Departament of English Language, Tikrit,Iraq.

( Received on 27/12/2020 - Accepted on 15/3/2021 - Published on 2/1/2022 )

DOI: https://doi.org/10.36586/jcl.2.2022.0.45.0248

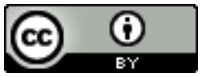

This work is licensed under a Creative Commons Attribution 4.0 International License

\section{Abstract}

The present study discusses the significant role of the historical memory in all the Spanish society aspects of life. When a novelist takes the role and puts on the mask of one of the novel's protagonists or hidden characters, his memory of the events becomes the keywords of accessing the close-knit fabric of society and sheds lights on deteriorating social conceptions in a backwards social reality that rejects all new progressive ideas and modernity. Through concentrating on the society flawing aspects and employing everything of his stored memory, the author uses sarcasm to criticize and change such old deteriorating reality conceptions.

Through reminding his community of the glories of their ancestors' bright legacy, Cela's work could be considered a wakeup call to bring life to, to revive the remains of the past and to save his country from the 
horror and miseries of the wars. Hence, the present study stresses all the author's teachings and constant lessons reflecting and filling the novel with symbols of the Spanish patriotism.

KeyWords : Novel, 20th Century, C. J. Cela , Mazurca Para Dos Muertos.

\section{El papel de la memoria histórica en el apoyo del concepto de pertenencia a la patria, en La Novela "Mazurca Para Dos Muertos", de Camilo José Cela}

\section{dr.qasem@tu.edu.iq}

Departamento de Lengua Inglesa, Facultad de Artes - Universidad de Tikrit, Iraq

\section{Resumen}

En esta investigación discutimos el gran e importante papel de la memoria histórica en todos los aspectos de la vida de la sociedad española, ya que el propio autor encarnaba a uno de los protagonistas de la novela a través de su memoria o llevaba la máscara de uno de los personajes de la novela. Personajes ocultos, pues su memoria de los hechos representó la clave para acceder a ese tejido social entrelazado, arrojó luz sobre muchos conceptos atrasados a la luz de una realidad social en deterioro, que vive lejos de la cultura y el conocimiento, y carece de lógica en su comportamiento, e incluso no quiere conocer ni siquiera tratar nuevas ideas que pidan desarrollo o lo que se llama modernidad. El autor empleó todo lo que almacenaba su memoria en criticar esa realidad, con el fin de cambiar algunos de los conceptos a los que estaba acostumbrado durante largas épocas, presentando las situaciones e imágenes miserables y vergonzosas de esa sociedad, además de utilizar frases mezcladas con ironía. El trabajo de Cela fue como un grito para despertar a la comunidad, ya que presentamos sus muchos intentos de revivir los restos del pasado que podrían beneficiar a su sociedad, y brindarles respuestas y consejos para salir de esa realidad 
deterioro, además de salvar a su país de los horrores y miserias de la guerra, recordándole las grandes actitudes y elevados valores que narran las glorias de sus antepasados y su gran herencia. Por tanto, nuestro foco en esta investigación estuvo en aquellas lecciones y sermones que fueron repetidos por el autor en fórmulas que sugieren y portan simbólicos que reflejan los significados de pertenencia y la identidad nacional española que llenaron las páginas de la novela.

Palabra clave: Novela, Siglo XX, C. J. Cela, Mazurca Para Dos Muertos.

\section{Introducción}

En esta investigación, arrojamos luz sobre el estado del conflicto psicológico y el papel de la memoria para inculcar el espíritu de pertenencia a los antepasados y abogar por la adhesión a los símbolos de identidad nacional del país en tiempos de caos y guerra lo que hace que las cosas no parezcan reales y cubiertas por ambigüedad, especialmente en una sociedad que estaba inmersa en sus instintos y deseos e ignoraba los acontecimientos que la rodeaban si esa es la memoria del individuo o de la sociedad española en general, donde la memoria de los acontecimientos históricos vividos por los españoles a pesar de la diferencia en algunas tradiciones de una región a otra, el simbolismo de la identidad española se incorpora a la religión y la historia más que otros símbolos como el idioma, el folclore y la moda, etc. En esta investigación, analizamos la " Mazurca para dos muertos ", publicada en 1983 del novelista español Camilo José Cela (1916 - 2002), famoso por sus críticas directas y su manera de tremendismo, que no escapa a filmar las escenas horribles de sus obras y descaradamente. El número de obras de Cela en todos sus géneros literarios, que alrededor de 80 obras.

Cabe señalar que su primer trabajo fue ( La Familia de Pascual Duarte), que se publicó en 1942 , y aún es famosa por su obras, Cela ganó un gran lugar entre los escritores españoles y ganó varios premios, los más importantes de ellos fueron, el Premio Nobel en 1989 y el 
Premio de Cervantes1995, fue nombrado en 1996 Marqués de Iria-Flavia por el rey Juan Carlos I .

La novela representó el grito de la conciencia humana que se restauró cuando la memoria recuperó imágenes de la historia en la mente del autor para anunciar el grito de dolor y un regaño de conciencia hacia los acontecimientos y variables que cavaron profundas heridas en el cuerpo de su país, España, lo que no debería haber ocurrido, sino por las comportamiento de la sociedad que se caracterizaban por la indiferencia, la irresponsabilidad y la falta de comprensión en un momento en que la sociedad española era prisionera de la ignorancia, la corrupción, el caos y la superstición, Cela intentó en las páginas de su novela, mostrar el estado de la sociedad gallega, que vive la duplicación de pensamiento y comportamiento, entre el idealismo y las concupiscencias, entre la verdadera fe y la superstición. Quizás lo que Cela reflejó de las imágenes del caos y la ignorancia en la sociedad gallega que representa la imagen de toda la comunidad española como resultado de desastres y guerras repetidas, que exponen a la sociedad española de conflictos internos y batallas con otros países a lo largo de su historia y su tierra fue el escenario de muchos eventos.

La descripción de Cela de la comunidad Galica, que vivía rodeada de aislamiento e introversión en una etapa que continuó desde principios del siglo XX hasta el final de la Guerra Civil Española, pero ciertamente que Galicia es la tierra cruda española que continuó practicando la agricultura y la vida simple lejos del desarrollo industrial y sus instituciones. Como tal notamos que en la siguiente cita "Ése es el caso típico de Galicia y del aislamiento tradicional del habitat rural." (Sanz, 2005, p.154)

La novela (Mazurca Para Dos Muertos), es una de las novelas históricas importantes que abordó la realidad de la sociedad española, especialmente la región de Galicia, en la que el autor quiso ser un modelo a través del cual refleje la naturaleza de esa sociedad impregnada en ilusiones y mitos en épocas que se dividieron en tres fases antes, durante y después de la Guerra Civil Española, en las que muestra la naturaleza 
de esa sociedad que vive aislada y en condiciones que exacerban los instintos y no le importan los hechos que suceden a su alrededor. La memoria histórica que fue acompañado por la voz de conciencia del ser humano que apenas llegó a oídos del autor, donde Cela reflejó en esta novela imágenes de dolor y remordimiento para la sociedad española.

A pesar de los cambios en la vida real de las naciones vecinas, los españoles aun viven lejos, aferrados a algunos de los remanentes de estas ilusiones y supersticiones, que son incompatibles con el contenido de sus patrimonio cultural y tradiciones, a menudo originadas por su Iglesia Católica ,especialmente la comunidad gallega. Este se aparece en estas líneas: "Puede decirse que la mitología popular gallega es, como dije al principio, una de las más ricas en personajes y seres míticos, cuyo conocimiento está muy arraigado a nivel popular aún hoy, lo que es una particularidad que la singularize y distingue positivamente de las de otras partes de España." (Sánchez , 2002, p.71-72) .

Cela destacó su crítica de la superficialidad de la sociedad y su ignorancia, y su búsqueda de instintos y deseos, al mismo tiempo que vemos conserva algunas tradiciones y rituales en su memoria de la historia. Esta duplicación de conceptos, presentada por Cela en la forma de un conflicto entre los deseos y los instintos del hombre, por un lado, y su afiliación e identidad por el otro, conduce a una falta de visión para definir los estándares de vida compatibles con los desarrollos de ideas en el mundo. Quizás Cela también se critique a sí mismo después de haber cambiado su actitud hacia esa guerra en la que participó.

Cela describó las características de la pertenencia de la sociedad española mostrando imágenes de la fuerza de los lazos familiares que formaron la estructura de la sociedad en ese período, lo que reflejó el conocimiento de la mayoría de los miembros de la sociedad gallega de sus orígenes y afiliaciones, a través de las palabras de los héroes y personajes de su novela, que se consideran las constantes básicas de sus sociedad. "Yo le vengo a ser de Vilar do Monte, entre el penedo Sarnoso y el outeiro Esbarrado y sé la leche que mamó cada criatura." ( Cela,1983,P.14). 
Se agrega en otro lugar para resaltar el estado de pertenencia a través de familias conocidas en la comunidad y los vínculos entre ellos, que Cela intentaba señalar que la sociedad expresa una facción o raza común .En otro ejemplo, cubría una gama más amplia de la sociedad, ilustrando los muchos vínculos de parentesco y vínculos entre sí en el tejido de las relaciones sociales en Galicia. "Somos todos parientes menos los Carroupos, que vinieron volando desde el otro mundo."( Cela,1983,p.14)

Cela pudo haber tratado de resaltar lo negativo de esa distinción en la sociedad española, a través de esta visión de los extraños, aunque al mismo tiempo se considera una especie de orgullo y pertenencia al lugar. Donde no puede tratar con los forasteros de sus orígenes, que no miembros de su facción de la misma manera, de modo que el extraño en sus ojos siempre está en duda y sospecha. Esta visión permanece constante a través de las generaciones, incluso si esos extraños han vivido con ellos en la sociedad durante muchos años. "Los Carroupos no se sabe de dónde salieron, del país no son, a lo mejor vinieron de la Maragatería," (Cela,1983,p.23) .

Cela explicó que la fuerza del tejido social depende de las familias numerosas conocidas como sus nombres y orígenes por todos los miembros de la sociedad gallega, donde la novela se repitió los nombres de varias familias que forman la base que estableció esa comunidad,por ejemplo,( los Gamuzo, los Guxindes, los Moranes, Los Vilagabe y los Carroupos, que se consideran extraños.) Intolerancia en la pertenencia reflejada por el autor en los sentimientos de verdad miembros de esa comunidad, ya que representan a las personas de la tierra, que tienen la capacidad de distinguir al extraño incluso a través de su apariencia. " $Y$ es morena de tez, a lo mejor es medio mejicana,” (Cela ,1983 ,P.25 )

El autor reflejó los aspectos negativos de esa sociedad, que tiende a dividirse según las razas, ya que ha aumentado las características del espíritu racista, en el que los dobles raseros se mezclan entre el racismo y la tendencia racial, que se desarrolla y refleja el atraso y la ignorancia de esa sociedad, que se basa en conceptos alejados de la lógica y de los 
lazos y los valores humanos. Tal vez Cela atribuya estas imágenes racistas a la ignorancia y el aislamiento de la sociedad de los demás, cuando muestra que la visión general de las personas hacia los extraños equivale a mirar a los enemigos, porque refleja la respuesta española a los ocupantes de su país a lo largo de la historia, que no se ha borrado de su memoria, y esto también podría ser las críticas de Cela a la sociedad, que vivió bajo la influencia de la fe católica hasta que la vio como el único y verdadero criterio de fe. Esto refleja la percepción de la enfermera, que debe tratar humanitariamente a los pacientes, pero también se caracterizó por ese espíritu cerrado hacia los extraños. "Para ella los soldados heridos éramos dos cosas, sagrados y de su propiedad; esto regía sólo para los españoles porque sor Catalina no admitía ni italianos ni moros." (Cela,1983,p.182 ). Creo que Cela expresó la imagen de tratar con los heridos, como en realidad lo vio cuando estuvo allí, donde que vivió ese período y participó en la lucha en esa guerra junto a las fuerzas de Franco, y también herido en esa guerra. A pesar de los dialectos diferencias y algunas tradiciones entre las ciudades españolas, pero los eventos históricos en su memoria colectiva representan el marco de pertenencia de todos los españoles. No hay duda que la memoria colectiva de los españoles se formó a través de las generaciones que han sufrido muchos eventos y conflictos, que hicieron la posición de la comunidad española se basa en ellos. La gente no quería ponerse en contacto con extraños con ninguna relación, incluso con el matrimonio, porque ven que lo mejor es preservar los orígenes españoles imbuidos de tradiciones, costumbres y religión.

En general, el aislamiento y la alienación de los demás han sido la característica dominante de la sociedad española, especialmente en esa etapa, porque lo encuentran ajeno a los demás, mejor para ellos y evitando sus preocupaciones y problemas. "Seguimos casi todos en nuestro sitio y sin tener que aprender otra lengua y otras costumbres," (Cela,1983, p.218).

El impacto de la guerra ha hecho vacilar a la sociedad, y la gente no puede hacer nada más que sus deseos y palabras de rechazo. Sin duda, ellos conocían las ideas destructivas que la guerra les trajo, que 
representaban herramientas para destruir a su sociedad, porque no encajaban con su cultura y sus valores ,las ideas son enemigos de España, no importa cómo pertenezcan, y debes levantarte y enfrentarte a ellas. "El Enemigo Malo recurre a mil argucias para incitarnos al vicio y alejarnos de la senda verdadera." (Cela,1983 , p. 70 ).

Sus fe absoluta y orgullo en los principios de su doctrina religiosa a lo largo de la historia, y como hemos mencionado anteriormente, se han convertido en lo mejor y lo más alto en comparación con otras sectas y religiones. Esta jactancia se refleja en las palabras de Don Jimeno. Lo que explicó la admiración de la gente por las posiciones de la Iglesia Católica a lo largo de la historia,Lo cual fue, para ellos, mejor que todas las demás ideas, incluso si requiere desarrollo y servicio humano. "Ahora circulan tendencias demoníacas y afeminadas, corrientes de pensamiento masonas." (Cela,1983, p. 243)

Las características de la afiliación y la adhesión al patrimonio religioso y cultural en la sociedad española, caracterizadas por una naturaleza espiritual . Está encarnado por su fuerte rechazo y oposición a todo lo nuevo, o no se ajusta a las tradiciones de la sociedad, ni siquiera a las apariencias o la ropa. "Y tus arreos no pueden ser las modas inmundas de la Francia judía y traidora," (Cela,1983, p.202)

Cela quería mostrar que la guerra era una consecuencia inevitable del comportamiento de esa sociedad, que vivía en una realidad llena de ignorancia y miedo a todo lo extraño, sin tratar de identificarlo y analizarlo, pero se despertó de su negligencia después de que fuera demasiado tarde, y el hombre español comenzó a sentir el tamaño del sufrimiento y el dolor, después de descubrir la devastación de la guerra, había destruido todo en su país, y se culpó a sí mismo, porque no le importaba lo que estaba sucediendo, antes de que ocurriera el desastre, y no escuchó la alarma, cuando estaba preocupado por sus instintos y emociones que eclipsaron su conciencia y pensamiento, y como resultado, no había oportunidad para que la sociedad se reformara, excepto por el sentimiento de tristeza y remordimiento. "Es como un 
castigo de Dios, lo más seguro es que hayamos ofendido a Dios con nuestros pecados." (Cela,1983 ,p.172)

Es cierto que la memoria comienzó su trabajo multiplicador en tiempos de crisis, desastres y dificultades, para formar una especie de escape de la realidad amarga, y tal vez para hacer una comparación entre los tiempos pasados y presentes. la guerra civil tuvo un gran impacto en la sociedad y en el hombre español, el lector puede ver y escuchar su resonancia a través de la memoria de los personajes y protagonistas de la novela que pudieron vincular los eventos con la historia y los eventos pasados, que en sus opinión formaron todos los modelos correctos para el mantenimiento del país que los antepasados vivían de acuerdo con sus tradiciones y costumbres asociados con los principios de la doctrina católica a pesar de todos los desafíos, por eso que pudieron resistir todos los desafíos y dificultades que enfrentaron ."Su pariente el santo Fernández murió confesando la religión católica, los infieles le decían iabjura de tu fe, perro cristiano!," (Cela,1983, p.71 )

Entre las manifestaciones de ese recuerdo que resonaron por las palabras de protagonistas de la novela, las fechas que estuvieron particularmente relacionadas con la fecha de los decretos con simbolismo religioso, como si la historia de España estuviera basada principalmente en eventos religiosos . "El día del Apóstol de 1808, a poco de renunciar Carlos IV a la corona de España.” ( Cela,1983 , p.70 )

El autor destacó la importancia de la historia para el personaje español, ya que representa las características de las glorias de los abuelos y sus heroicidades, que la persona española no puede vivir sin esa herencia . El estado de remordimiento y conciencia se convirtió en inherente a la vida del hombre español durante ese difícil período, como una especie de remordimiento por su gloriosa historia, o una reacción debido a la memoria que restauró los rasgos de las brillantes imágenes de la historia de España y dejó al hombre español hablando, hoy no podemos pertenecer a esas generaciones de grandes personas, especialmente en un momento en el que nos enfrentamos en una guerra que no es honorable. 
"Con remordimiento, en el bruñido espejo de Isabel y Fernando nos miramos todos los españoles," ( Cela,1983,p.202).

En otra página, el autor se refiere al simbolismo de los tiempos bendecidos y sagrados en la memoria colectiva de los españoles, donde que los eventos históricos relacionados con la doctrina católica constituyen una gran parte en las almas de los españoles, hasta el punto de la santificación, a través de la repetición de recuerdos eternos a través de las edades, en sus días, meses y años, como se reflejó en el calendario gregoriano, que se usa hasta hoy. "La carretera general ZamoraSantiago, la N-525," ( Cela,1983, p.62) . Ese orgullo del pasado que mostraba la sociedad española fue una buena calidad que indica la profundidad de pertenencia y el orgullo de identidad, pero si la vida de una persona y la sociedad se basa solo en recuerdos, entonces esto es algo que no ayuda y no sirve a ninguna sociedad, como si cavara en las tumbas.

Por lo tanto, la crítica de Cela a los casos que reflejan claramente el subdesarrollo de la sociedad y su ignorancia, en su distancia de la realidad y de la lógica que debe ser compatible con la mente, para seguir el camino del progreso y el desarrollo de la sociedad similar a otros pueblos europeos. Destaca una de esas imágenes expresivas de ese concepto que explica la cultura de la sociedad basada en mitos. "En Galicia aporque están muertos y encantados y andan por debajo de tierra." (Cela,1983, p.107)

Aquí, Cela no dijo a través de sus percepciones sobre la realidad de la sociedad, ya que parece que esto existe en la memoria colectiva de la sociedad, especialmente la gallega. "Estos mouros viven bajo tierra o bajo y mámoas , y se les considera los pimeros habitants de Galicia ." ( Sánchez , 2002, p.69)

La tragedia de esa guerra, que fue una lucha entre las constantes y las variables, entre las personas mismas, entre las ideologías que piden desarrollo y liberación, y otras que piden la adhesión a valores y principios, hace que el caos haga que el hombre no sepa el lado correcto 
y al mismo tiempo escucha el sonido del recuerdo lejano, escucharlo decir les que lo que vivimos hoy es el peor de todos los tiempos y épocas, y creen que los tiempos anteriores, especialmente lo que se llamó la Edad Media, fueron mucho mejores que la era actual, lo que hizo que las personas se tambalearan como borrachos debido a la influencia de las ideas materiales, que no resonaron en la realidad de la sociedad, vivieron según los principios de la fe y los valores humanos. “Lo más probable es que fuera mejor que la Edad Contemporánea, a pesar de la radio y los aeroplanos."(Cela,1983, p. 91).

Además, Cela quería decir que las ideas que surgen en sociedades que piden revoluciones y guerras, que no dan valor a una persona y no respetan su naturaleza, sin duda se basan en una deficiencia, ya que considera al ser humano desde el punto de vista del materialismo abstracto de todos los sentimientos y emociones y, como resultado, será inútil , y solo traerá dolor y privación. La posición de Cela es clara en su crítica de esa guerra, y todas sus consecuencias, de la muerte y destrucción del hombre y la naturaleza, y en contra de las leyes celestiales y sin lógica. Cela señaló que el sacrificio de espíritu y la muerte en la guerra, que no tiene un significado real para defender la tierra o la soberanía o valores superiores, es una especie de estupidez. "Lo malo es la risa que da a los que quedan vivos." (Cela,1983,p. 21)

Cela enfatizó que el desacuerdo en las ideas o conflictos puede ocurrir entre las personas que viven en el mismo estado, pero no puede llegar a la guerra entre ellas, especialmente cuando esas ideas son poco claras y sospechosas, considerándolas como una ausencia de razón y locura . " $Y$ entre españoles! Esto es cosa de locos.”( Cela,1983,p.160 )

El autor criticó implícitamente las ideas materialistas, que ven que el hombre es solo una de muchas cosas, y no ven el lado espiritual y el valor supremo del hombre en existencia y condena la guerra, que representa nada más que una lucha intelectual entre quienes están detrás de estas ideas. En cuanto a las personas inocentes que ingresan por su ignorancia, serán las únicas víctimas que se perderán a sí mismas y a sus vidas. Por lo tanto, describe guerras que no se basan en una base honesta 
que merece sacrificios, como un juego para matar, y por lo tanto, se opone a todas las reglas de la fe celestial y los principios humanos, porque el espíritu humano es precioso y no puede ser comprometido. " $L o$ malo de las guerras es que cortan las vidas antes de madurar, eso es ir contra la ley de Dios." (Cela,1983, P.158)

Por lo tanto, a través de estas actitudes críticas hacia la guerra, y las imágenes presentadas por el autor, a través de las palabras de los personajes de la novela, explicaron la actitud general de los españoles en la guerra, y quizás del autor mismo, de que era un retroceso y un punto negro en el frente del país, debido a que no trajo a la comunidad solo la miseria y el caos, e hizo que las voces vulgares sean el control del destino del país, cuando los dueños de valores y principios se vuelven débiles, como resultado de este miedo y horror, la sociedad se ha vuelto orgullosa de las heroínas vacías del contenido y sin ningún significado humano.

Este estado de deterioro social ha llevado a sospechas generalizadas entre las personas, además de sus seguidores de la forma de pensar que se basa en una comparación entre el pasado y el presente, entre los valores y tradiciones que fueron una de las razones de la fuerza y la cohesión de la sociedad, que contradice los elementos de la sociedad actual, que se desvió hacia las ideas materialistas que lo hicieron abandonar todos sus valores y principios, por ejemplo las circunstancias de los hombres en el pasado que encarnan todas las formas de torneos, a través de la memoria que describe la fortaleza física y mental de los hombres y su capacidad para enfrentar desafíos comparado con el débil hombre español en esta época miserable.

Además de la corrupción en la moral que se convirtió en un contexto natural en la sociedad, sin ningún control o respeto por las normas sociales que prevalecían, aquí debe señalarse que Cela quería enfatizar el estado de ignorancia en la sociedad, ya que las personas no entienden la verdad y el contenido de las ideas. Lo que exige el desarrollo que pueda servir a la comunidad, pero solo atienden a los aspectos que simulan la emancipación de sus instintos de las restricciones sociales, es decir, retrocedieron dentro de la tendencia materialista individual, no basada en 
el servicio comunitario y el fortalecimiento de los lazos de pertenencia entre sus hijos.Esa descomposición moral de la sociedad no fue por la pobreza y la necesidad, sino que incluía todos los estratos de la sociedad. "El adulterio se da con frecuencia en las mejores familias." (Cela,1983,p. 117).

Quizás el impacto de las ideas que involucran materialismo, tuvo un gran papel en el desmantelamiento de los valores fijos en la sociedad, que se consideró uno de los principales pilares de la conciencia y la cultura de la sociedad, especialmente la institución religiosa, cuya imagen se empañó como resultado de la influencia de esas ideas, y por otro lado, porque la corrupción ha llegado a los hombres de la institución misma. Representados por hombres de la iglesia, y por lo tanto ya no tienen el mismo papel que desempeñaron en la sociedad. Esto se refleja en las palabras de Raymond, cuando ya no confiaba en el clero que se había alejado del camino correcto y estaba influenciado por ideas contrarias a las enseñanzas de la Iglesia Católica . "Creía en Dios (él prefiere decir el Sumo Hacedor) pero no en los curas, eso parece de masones."(Cela,1983,p.112)

Los clérigos se interesaron en asuntos personales y entraron en el ciclo de corrupción, se sumergieron en sus deseos y siguieron sus instintos animales y materiales, hasta que su imagen se distorsiona ante los ojos de la gente. El desprecio por el clero continúa, mientras están comprometidos con sus placeres y deseos, y abandonando su deber sagrado, que debe caracterizarse por la ética del ascetismo .Esto se refleja en la descripción de un clérigo. "Vive rodeado de moscas, a lo mejor es que tiene el gusto dulce.”( Cela,1983, p.18)

Bajo el caos y la corrupción que prevalecía en la sociedad, surgió un estado de cuestionamiento y crítica de todos los rituales libres de fe verdadera, que ya no son válidos ni tienen efecto en el hombre, porque perdieron el significado ideal que encarna el espíritu del pasado y sus enseñanzas. Como en la respuesta del soldado herido a la enfermera. "Se lo digo con todo respeto, señorita, pero para mí que el Sagrado Corazón es gafe." ( Cela,1983, p.182). Pero a pesar de toda esta degeneración en 
los principios, hay cosas arraigadas en la mente del hombre español que no se pueden olvidar en absoluto,como se mencionó anteriormente, los dobles estándares en la sociedad, en tiempos de caos, no impidieron que el hombre español se enorgulleciera de su identidad y doctrina, y no acepta a las personas que siguen otras doctrinas, como se afirma en las palabras del sacerdote, que refleja implícitamente las características del racismo . "¡Ni que fuera maricón! iY este otro por los protestantes, menudos cabrones! ¡Muera Lutero!’( Cela,1983, p.87)

Parece que la guerra dejó su huella en la sociedad a través de sus ideas que hicieron que la sociedad renunciara a muchas de sus tradiciones y patrimonio cultural, y todo lo que se remonta al pasado, que abandonar los principios se volvió más fácil que mantenerlos, incluso incluido los símbolos y nombres que no escaparon a ese efecto. "A las niñas hay que ponerles nombres de vírgenes o de santas, no nombres laicos y de dudoso gusto: Rosicler," (Cela,1983,p. 43)

Era un conflicto de la memoria histórica con la realidad creada por la Guerra Civil , los hitos y las tradiciones cambian gradualmente a través de la influencia de conceptos nuevos y extraños, lo cual no sirvió a la sociedad sino que le hizo vivir en el caos y la miseria, que no dejará nada en la memoria del hombre español, excepto los gritos de su conciencia continuaban y llamaban a aferrarse al pasado como un lamento por todo lo que la sociedad ha perdido. También la conciencia del autor y las personas honorables que aman a España llorando por la realidad de su país, que ya no distingue entre lo maligno y lo bueno, y tratan por todos los medios de mostrar su adhesión a su comunidad. "Sea limpia y obediente y hable las dos lenguas, el gallego y el español, lo demás es todo de adorno."( Cela,1983,p.140)

La conciencia que debilitó su voz, y se convirtió en un himno de dolor, se puede escuchar haciendo eco en las esperanzas y los sueños, tal vez encuentre a quién que restaurar la herencia que está desgarrada en las articulaciones de la guerra, en referencia al líder nacional, que todas las personas están esperando, para revivir el espíritu de pertenencia a España 
y recuperar su identidad, después de destruir todo. "La gente ha perdido el respeto a la costumbre, ipobre España," (Cela,1983, p.139).

Las características de la desesperación eran muy claras, como resultado de lo que vio en la realidad de la miserable sociedad, sumergido en el vicio, viviendo en la pobreza, donde la guerra incrementó su atraso y su ignorancia ,el autor expresa esto en las palabras de Robín Lebozán, describiendo la vida de su familia bajo esta ignorancia y caos. " $M i$ familia es como Venecia, Moncha, como la ciudad de Venecia, que vive de recuerdos y se va hundiendo poco a poco y sin remisión," (Cela,1983,p.198 ). Los gritos de esa conciencia no se detienen tras la pérdida de la esperanza, su voz se eleva para recordar a la sociedad, que el valor de la identidad y la pertenencia es grande, e insta a los dueños del espíritu nacional a volver al compromiso con la moral, porque las generaciones que no son éticas, no pueden servir a su comunidad, así es Cela a menudo enfatiza el retorno a la moralidad, siendo la verdadera imagen que refleja el valor del país y la cantidad de pertenencia y compromiso con la religión, el simbolismo de la decencia es uno de los cimientos de la religión ,por lo tanto, la desaparición de la decencia significa que no hay una verdadera religión. "Los niños y niñas deberán usar traje de baño completo desde los dos años de edad, la moral debe nacer con el individuo,"( Cela,1983,p.202)

Cela describó la posición de la persona española frente a esa miserable realidad,que destruyó todo, que quiere correr hacia adelante, no quiere mirar hacia atrás. Porque una comparación con el pasado le causará dolor, ya que ve todos los valores de ese pasado antiguo destrozado ante su ojos, eso hacer que la voz de la conciencia grite y reprendiendo a las personas por sus acciones, incluso se volvió molesto y aumenta la miseria del hombre, y el hombre esperaba detener su memoria y borrarse, para escapar del castigo del yo. "Nuestros recuerdos eran traidores y marchitos, a mí me gustaría no tener ni pensamientos ni recuerdos pero no puedo,"( Cela,1983, p.233)

España está agotada por el desastre de la guerra,nadie se libró de su daños, el hombre y el animal, dejó la tristeza flotando sobre los cielos del 
país, porque las ideas diabólicas que llamaban a la guerra, no solo trajeron la ruina a España, pero también hizo que los significados y propiedades de las cosas cambiaran a los ojos de las personas. Esto encarnaba la posición de Cela cuando lamentó su país mientras veía la destrucción y olía a muerte en todas partes, incluso la lluvia, que representa la misericordia de la tierra y la naturaleza, ha cambiado su carácter en la magnitud simbólica del desastre causado por la guerra del dolor y el sufrimiento, y fue la encarnación del llanto del cielo en esta tierra problemática ."A lo mejor llueve sin galana cortesía, ni rendido amor, ni mansa y benevolente serenidad," (Cela,1983 ,p.207)

Cela describó la guerra como no traer la tristeza y el dolor de quienes la encendieron, pero toda la miseria y el sufrimiento estuvo en los hombros de la gente común, que no podía hacer nada, aquellos que no tuvieron otra opción o decisión de hacer erupción, pero este es siempre el caso de los pobres, llevan los errores que otros cometen. "No mató al lobo, la guerra fue del hombre contra el hombre,"( Cela,1983,p.204)

El autor terminó la tragedia de esa guerra en su novela con mucho dolor y más pena y muchas imágenes de destrucción, privación y desplazamiento, dejadas por la guerra en su país, España ha perdido su valor y posición entre las naciones, y ha debilitado el sentido de pertenencia de esa sociedad que mantiene su identidad. Los restos de guerra presentados por Cela con diferentes imágenes de la vida de la sociedad española, y no olvidó mencionar el estado de desintegración social y familiar, que se convirtió en lo contrario de lo que era en el pasado , como resultado de los efectos psicológicos dejados por la guerra, donde la desaparición de esos lazos sociales fuertes y familiares que fueron motivo de orgullo de origen y pertenencia en el pasado,porque la desesperación y el pesimismo abrumaron todos los aspectos de la vida. "Ahora las familias están más dispersas, cada uno va por su lado." (Cela,1983, p.216)

La tragedia de las guerras y sus devastadoras consecuencias no han disminuido por los efectos psicológicos negativos que dejaron en el hombre, sino que superan todo, incluso la geografía del país. Este énfasis 
en resaltar los efectos devastadores de las guerras por parte de Cela reflejó su crítica implícita a la sociedad y al hombre español que se apresuró detrás de ideas y movimientos revolucionarios ilusorios que solo trajeron la ruina a su sociedad, y cuando la gente perdió todas las esperanzas de regresar a su país al pasado, solo tienen la última esperanza de ver a sus país antes de que sea demasiado tarde. "-España es un cadáver, Moncha, no quiero pensarlo pero me da mucho miedo que sea un cadáver," (Cela,1983.p.207).

Él suspira mucho por lo que pasó en su país, y elogia los remanentes de las características de pertenencia a su gente, que conservó una pequeña chispa del orgullo en la identidad, representado por algunos valores y tradiciones, que no fueron abandonados por la sociedad a pesar de la magnitud del desastre que le sucedió. Cela muestró las imágenes de esos modelos nobles en la sociedad española, quienes no renunciaron a su pertenencia y tradiciones a pesar de toda la devastación causada por la guerra y convirtió el territorio español en cementerios, en las palabras de Ádega. "Yo soy de esta tierra y de aquí no me echa nadie; cuando muera me convertiré en la tierra que da de comer a los tojos." (Cela,1983,p.25)

Y muestró que el asesinato del alma humana nunca se acepta, y no los principios de la sociedad, y concluye su novela con una posición que refleja los significados y el simbolismo de la identidad española, que se refleja en el compromiso con las costumbres restantes del pueblo español, a través de la ejecución del asesinato del asesino que merece la pena , por Matisse, y al mismo tiempo Cela reflejó la misericordia del hombre español incluso en este caso y no la sed de matar como otros, sino solo para mantener sus hábitos y tradiciones que no abandona. "No soy yo quien te mata, es la ley del monte." (Cela,1983,p.249).

Esta venganza es una forma de justicia celestial y está justificada por las tradiciones y costumbres de la sociedad, y es un indicio de que los españoles no abandonaron sus costumbres y tradiciones en la aplicación del derecho humano asociado a sus enseñanzas religiosas y costumbres sociales.Cabe señalar que la palabra "asesinato" apareció en las páginas 
de la novela aproximadamente 71 veces. Tal vez el papel de la memoria sea excelente para mantener esa llama ardiente en el corazón de algunos, a pesar de la cantidad de dolor causado por la memoria al ser humano, pero al mismo tiempo restaurar la esperanza, porque es como una fuente para estimular la reserva restante del espíritu de pertenencia.

Si es necesario que Gaudencio tocó la melodía Mazurca, porque el renacimiento y la aplicación de la tradición merecen esa melodía, como en el caso de la muerte y la pérdida de una persona que tiene un buen papel en la sociedad. "Interpretó la mazurca Ma petite Marianne con muy especial deleite, la estuvo tocando hasta la madrugada."( Cela,1983,p.249)

Cabe señalar que Cela mencionó en su novela muchos símbolos que indican las características de la pertenencia, la mayoría de los cuales expresaban el espíritu de pertenencia y la identidad nacional española a la sociedad y al propio autor. Podemos recordar algunos de ellos : El nombre de Cervantes. El simbolismo de los nombres de las personas que llevan los significados y tradiciones religiosas de la sociedad española ( Ignacio, Carmen, Jesús , Sara .etc.) . Rituales simbólicos y actos religiosos, cabe destacar que San Juan, cuya celebración es la más importante en Galicia de todas las demás ocasiones religiosas ,ha sido mencionado varias veces en la novela. "Fiesta de San Juan, una de las más curiosas , gráficas y queridas del pueblo." (Murguía ,1888, p.191).

También los números seleccionadas por Cela, con el simbolismo como en el número (525) mencionada anteriormente y también en el número de caballo Peaty Sandy № (21) en la página 197 . "En la biblia el 21 es el número de los atributos de la sabiduria divina." (Salas,2009, p.256)

Además de muchos términos y frases simbólicas, como la Cruz Rosada, y también los nombres de los perros de Tanis, que Cela quería reflejar algunas de las características y significados, no queremos centrarnos en su semántica aquí, excepto mencionar uno de ellos (Morito) ,que representa el título de una de las grandes familias que fueron las primeras en ingresar a América. 
Quizás Castilla representa el gran símbolo nacional de conciencia y memoria colectiva de los españoles, lo que Cela no olvidó, cuando él indicó implícitamente su papel a través del carácter del juez, en un signo de su posición en el establecimiento de la entidad social española de acuerdo con los fundamentos religiosos basados en la igualdad, "Porque el señor juez era mиy serio, era un castellano muy remirado que se llamaba don León."(Cela,1983, p.17). Y sigue siendo la piedra angular de la historia española hasta nuestros días. "el papel histórico de Castilla, su vinculación con la idea de España , así como su participación en el conjunto del desarrollo historico.” (Román. 2009. p.18)

Los atributos de santidad que llevaban el título de la novela, especialmente "melodía de Mazurca "Contiene simbolismo que expresa de una forma u otra la naturaleza y características de la persona española, que usualmente tiende a sus sentimientos consistentes con su imaginación y está impregnado de espiritualidad, a diferencia de otros que viven su vida en materialismo para tener en cuenta al lector, una foto del español que vivió durante la Guerra Civil.

Terminamos la investigación con una parábola popular,lo que Cela usó para expresar ese contenido. "Cuando se hace un silencio los españoles dicen que pasa un ángel y los ingleses que ha nacido un pobre.'(Cela,1983, p.204)

\section{Conclusión}

La memoria del hombre o la sociedad significa su personalidad e identidad, porque encarnan el curso de sus vidas, especialmente la memoria histórica, que desempeña un papel importante en la grabación y preservación de los eventos, y puede sustituir al historiador,o toma su lugar en su ausencia o falta de credibilidad en la transferencia de los eventos.

La investigación reveló la importancia del papel de la ciencia en la vida humana, porque es la única manera de lograr la vida apropiada para el hombre, donde el hombre, y en cualquier sociedad, debe crear un estado de equilibrar las ideas modernas sobre la sociedad con su herencia 
cultural y las tradiciones de su sociedad y no exceder ni descuidar uno de los lados, porque las ideas son temporales y urgentes, pero la pertenencia y la identidad son la entidad de la persona misma, y perderlo significa el fin de esa persona o sociedad.

\section{Referencias}

- Cela,.Camilo José Cela , Mazurca para dos muertos , Planeta Pub Corporation, 1983 , 266 páginas.

\section{Bibliografía}

Arnaldo F. Santos Sanz , Monarquía o república: consideraciones acerca del significado político de la actual democracia española , Editorial Fundamentos, 2005 . 350 páginas.

Bernard , Christian Bernard . Reflexiones de un Rosacruz , Ed. Rosacruces, SL . Barcelona, 2011 . 202 páginas.

Edited by Paul Aubert, Religión y sociedad en España (siglos xix y xx): Seminario celebrado en la Casa de Velázquez (1994-1995), Casa de Velázquez, 2002 - History - 292 páginas.

Eds. Manuel Redero San Román, María Dolores . Castilla y León en la Historia Contemporánea . Ediciones Universidad de Salamanca. 2009 . 684 páginas.

Manuel Murguía, España, Sus Menumentos y Artes - Su Naturaleza e Historia , Galicia, Part 1, Ed. Daniel Cortezo YC. Barcelona ,1888 . 1196 páginas.

Salas, Emilio Salas , El Gran Libro del Tarot, Ed. Robinbook S.L., Barcelona . españa . 2009 - - 384 páginas.

Sánchez, Manuel Martín Sánchez, Seres míticos y personajes fantásticos españoles , Ed. EDAF, S.A.Madrid, 2002 , 599 páginas. 


\section{References}

Arnaldo, . F. Santos Sanz, Monarchy or republic: considerations about the political meaning of the current Spanish democracy, Editorial Fundamentos, 2005. 350 pages.

Bernard, Christian Bernard. Reflections of a Rosicrucian, Ed. Rosacruces, SL. Barcelona, 2011. 202 pages.

Cela , .Camilo José Cela, Mazurca for two dead , Planeta Pub Corporation, 1983, 266 pages.

Edited by Paul Aubert, Religion and society in Spain (19th and 20th centuries): Seminar held at the Casa de Velázquez (1994-1995), Casa de Velázquez, 2002 - History - 292 pages.

Eds. Manuel Redero San Román, María Dolores. Castilla y León in Contemporary History. Editions University of Salamanca. 2009. 684 pages.

Manuel Murguía, Spain, His Menumentos y Artes - The Nature and History of it, Galicia, Part 1, Ed. Daniel Cortezo YC. Barcelona, 1888. 1196 pages.

Salas, Emilio Salas, The Great Book of the Tarot, Ed. Robinbook S.L., Barcelona. Spain . 2009 - - 384 pages.

Sánchez, Manuel Martín Sánchez, Mythical beings and Spanish fantastic characters, Ed. EDAF, S.A. Madrid, 2002, 599 pages.

\section{About the author}

\section{Assistant Professor Dr. Qasem Mohammed Helal Saleem}

he obtained a master's degree in Spanish literature from the same university in 2005. In 2013 he received his $\mathrm{PhD}$ in Spanish and Comparative Literature from Voronezh University-Russia. 
$\mathrm{He}$ is currently working at Tikrit University- College of ArtsDepartment of English Language and Department of Translation.

Orcid ID: https://orcid.org/0000-0002-0656-4953

E.mail -dr.qasem@tu.edu.iq

\title{
دور الذاكرة التاريخية في تعزيز مفهوم الانتماء للوطن في رواية " لحن



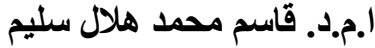 \\ جامعة تكريت ـ كلية الاداب ـ قسم اللغة الانكليزية
}

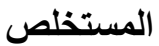

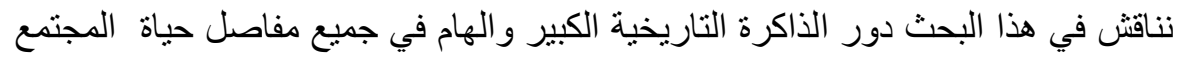

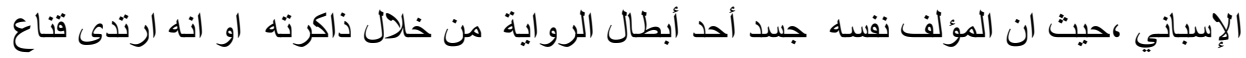

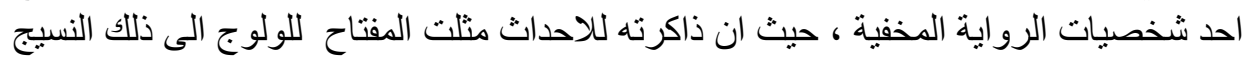

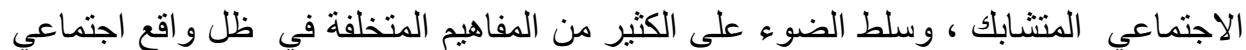

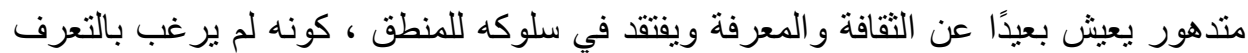

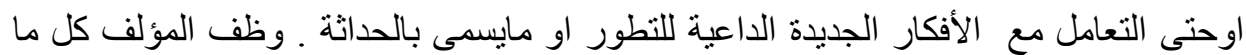



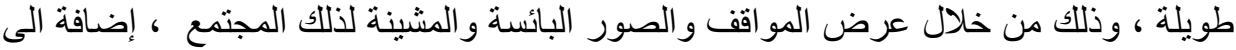

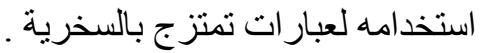

كان عمل ثيلا بمثابة صرخة لاجل إيقاظ المتمع ، حيث عرضنا محاو لاته الكثيرة وهو

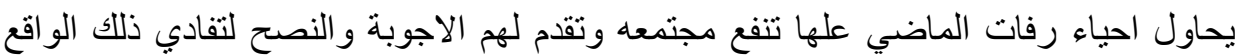

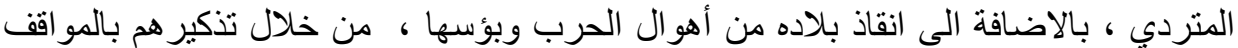

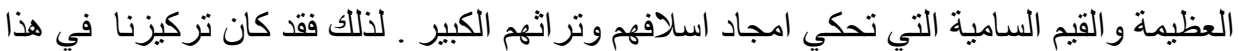

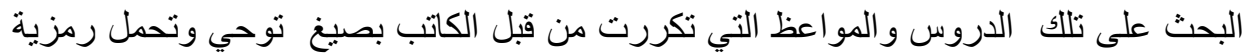
ومعاني تعكس معاني الانتماء و الهوية الوطنية الإسبانية التي ملأت صفحات التئ الرواية. الكلمات المفتاحية : الرواية ، القرن · ب ، ك.خ. ثيلا ، لحن الماتوركا على مينين . 